\title{
One electronic document accepted by importer and exporter authorities: Blue Path as an element of integration and traceability
}

\author{
Maria L. R. P. D. Scoton ${ }^{1,}$, Anderson O. de Souza ${ }^{1}$, Flávia R. P. de Lima ${ }^{1}$, Vidal A. Z. C. Melo ${ }^{1}$, Luiz N. Rossi ${ }^{1}$, Eduardo M. \\ Dias $^{1}$ \\ ${ }^{1}$ GAESI - Grupo de Automação Elétrica em Sistemas Industriais, Escola Politécnica da Universidade de São Paulo, Av. Prof. Luciano \\ Gualberto, trav 3, $n^{\circ}$. 158, CEP 05508-970, São Paulo/SP, Brazil, http://www.gaesi.eng.br.
}

\begin{abstract}
The Blue Path (CA-e) is an document created and transmitted electronically that contains all necessary data to allow the sanitary authority to analyze the requirement of exportation that will result on the sanitary clearance of the animal protein for exportation. Actually it is in use in Brazil. However, even though the data exists electronically, when it is send to the importer country some must be sent on paper, because the bilateral agreements do not allow the exchange of electronic documents. The present work proposals the extension of the CA-e, as an element of integration and traceability, that will allow the automation of the communication between private and public systems not only at Brazil, the country of the origin of the animal protein exported, but also between and at the country of destiny. Based on the number presented by the adoption of the CA-e at Brazil, it is fair to conclude that this communication machine/machine would bring great economy and optimization for the supply chain.
\end{abstract}

\section{Introduction}

Electronic documents (e-Docs) are not novelties; however, their level of adoption is still low if compared with its potential. [1] An example of that are the international trades that demand the use of paper documents instead of electronic ones. Observe Brazilian animal protein supply chain that, on 2012, had about 200 million heads of cattle and 22 million cattle slaughtered, and, on 2010, generated a turnover of US\$167.5 billion. [2] Brazilian animal protein exportation process demands documents on electronic format, such as the electronic invoice, known in Brazil by the acronymic NF-e, but, also demands paper documents, like the International Health Certificate, CSI, acronymic from its name in Portuguese. [2]

As verified by a pilot project, the dependency of documents on paper resulted on an extra 57 hour on the exportation through Port of Santos (at city of Santos, state of São Paulo), and on an extra 109 hour on the exportation through Port of Navegantes (city of Florianopolis, state of Santa Catarina). [3] Brazil has to improve its process to be more competitive, considering he was the 124 country, between 189 analyzed, on the business regulations aspect, which "measures the time and cost (excluding tariffs) associated with exporting and importing a standardized cargo of goods by sea transport. The time and cost necessary to complete every official procedure for exporting and importing the goods are recorded; however, the time and cost for sea transport are not included. All documents needed by the trader to export or import the goods across the border are also recorded". [4]

The cause of this extra time was the necessity to make the inspection request, called "request for exportation" (RE), and all the papers that accompany it, get to the International Agricultural Surveillance, known in Brazil as Vigiagro. Vigiagro is the institution responsible for analysing the RE. This document results on the cargo being granted or not a heath certificate to exportation. This analysis, as timed during the pilot took around 4 minutes. No analysis took more than $30 \mathrm{~min}$. [3]

In a nutshell: the bureaucratic process can occur independently of the physical one. This is what is shown of Fig. 1 [3]:

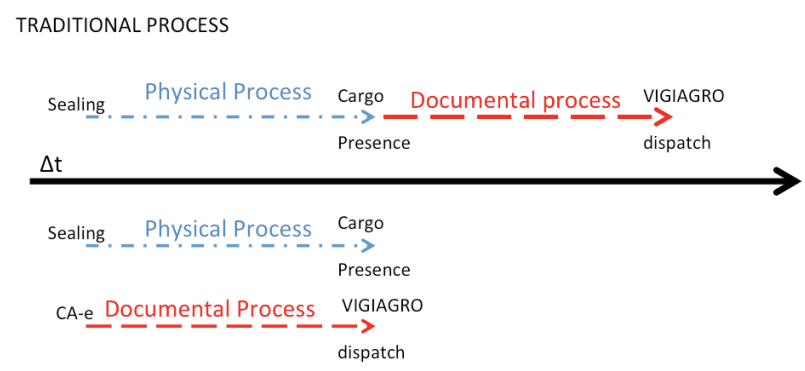

PROPOSED PROCESS (CA-e)

Figure 1. Graphic comparison between the traditional process and the proposed process (CA-e) [3]

Therefore, if Brazilian animal protein supply chain adopt an e-Doc that (a) will be available as soon as transmitted to the back office; and (b) contains all

\footnotetext{
$\overline{{ }^{a} \text { Corresponding author: lidiadias@ }}$ pea.usp.br
} 
information necessary for Vigiagro's analysis, it will be possible to Vigiagro to analyze the RE just after this cargo is sealed. Therefore, the following process will no longer happen:

1. Collection of the documents that accompanied the cargo by a employee of the customs broker;

2. Delivery of the collected documents to the customs broker;

3. Issue RE, by the customs broker;

4. Delivery of the RE to the Vigiagro at a Vigiagro's unit; and

5. Withdraw dispatch at Vigiagro
The only thing that will remain from the conventional process is the analysis and dispatch of the RE by a Vigiagro agent, which will be available on line.

This, as verified on some practical cases represents a significant gain of time because, by having the documents available electronically, the RE analysis can occur independently of the cargo physically arriving on the terminal, which will optimize the clearance of the cargo. Fig. 2 presents the days that took to complete the conventional process (based on paper, red line) and the electronic process (with CA-e, green line). Based on that, it also shows the time economy in days for the protein exportation to the listed countries (purple line). The blue columns represent the total of containers measured per country.

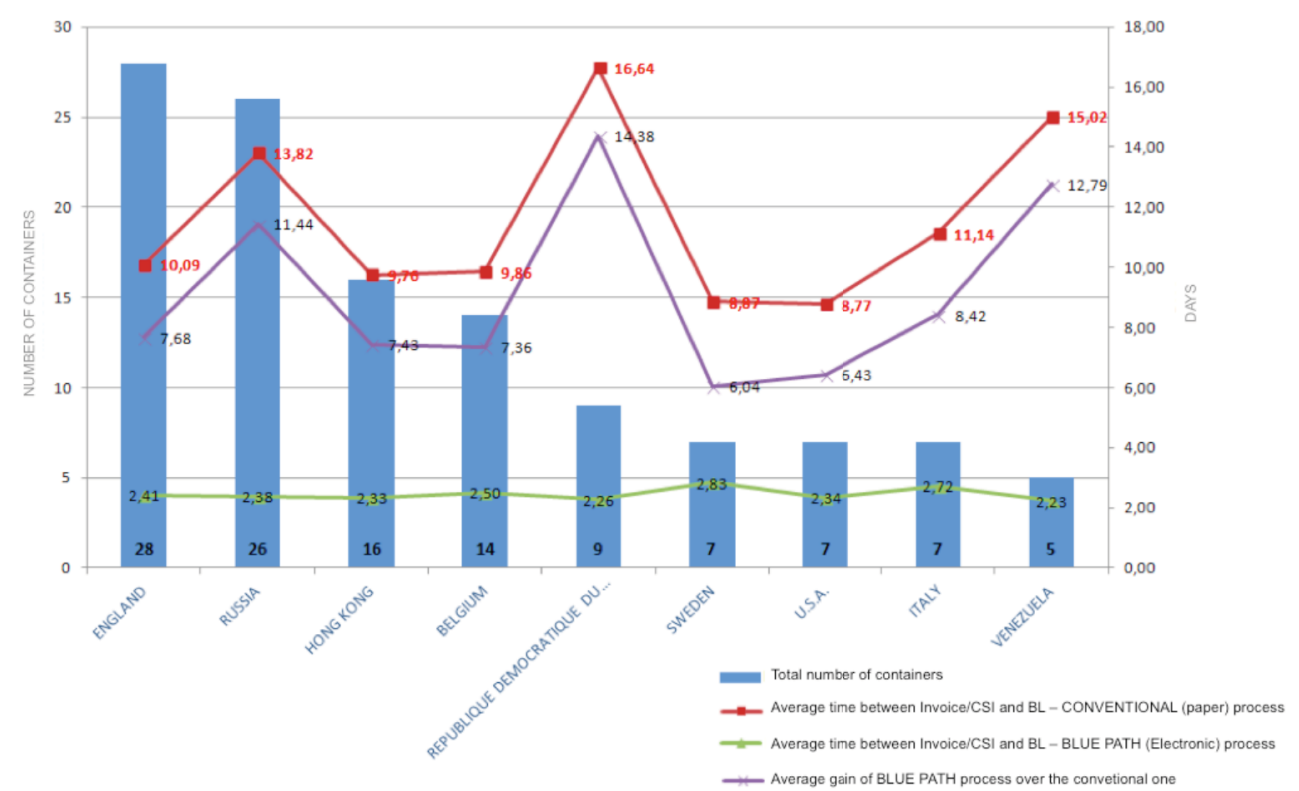

Figure 2. Time economy of electronic process based on data collection of days necessaries to complete conventional process and process with Blue Path

Those are the time economy measured only at the Brazilian part of the process. However, this process will continue on the importer country. The need for a paper document can occur because of requirements inside of a country, but also requirements inside of the importer country. This depends of bilateral agreements between those countries. If the importer country does not accept the electronic document, a paper document will have to be issued anyway to be sent to the importer (or its representative). Thus, the level of bureaucracy probably will be higher than it could, impacting on the competitiveness of that supply chain.

Having in mind the animal protein international commerce, the present work proposes to extend the adoption of the CA-e, extending its function as an element of integration and traceability since the industry until the port of destiny. This will allow the information to get faster to the importer and authorities of the importer country, in a more secure and efficient manner. Given the CA-e is based on machine/machine communication, it will diminish errors, inefficiency and reworks.

\section{CA-e}

It is possible to diminish the amount of bureaucracy through Brazilian beef supply chain by adopting an e-Doc that allows the analysis of the required information before the arrival of the cargo at the border; the CA-e is an example of that [2 e 3].

Actually, the CA-e acts over animal protein exportation supply chain, more exactly over the health clearance of the cargo. Besides the parties of the contract of purchase and sale, this process involves industry, Ministry of Agriculture, and Provisioning of the Land (MAPA) broker, transportation companies and ports. So far, it does not involve the Internal Revenue Service of Brazil (RFB) or the port of destiny.

At the industry, as shown on Fig. 3, the following steps are taken: 1. fabrication of the product; 2. load unitization; and, 3. generation of traditional operational documents. 

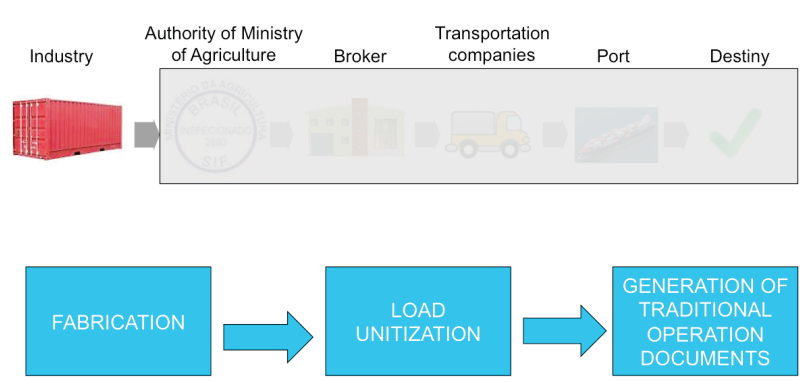

Figure 3. Brazilian animal protein exportation supply chain: processes realized at the industry.

At the exit of the industry acts the fiscal of the MAPA, who, as shown on Fig. 4, must: 1. verify cargo and documents; 2 . seal the container; 3 . generate the CAe; and, 4. transmit the CA-e to the system BackOffice. By doing so, the information will automatically be available for those previously registered on CA-e system.

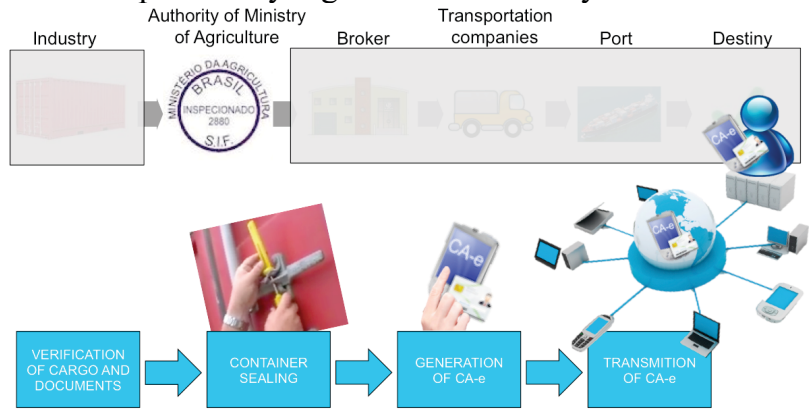

Figure 4. Brazilian animal protein exportation supply chain: processes realized at the exit of the industry by an authority of MAPA.

The CA-e operational model is explained on Fig. 5 and Fig. 6.

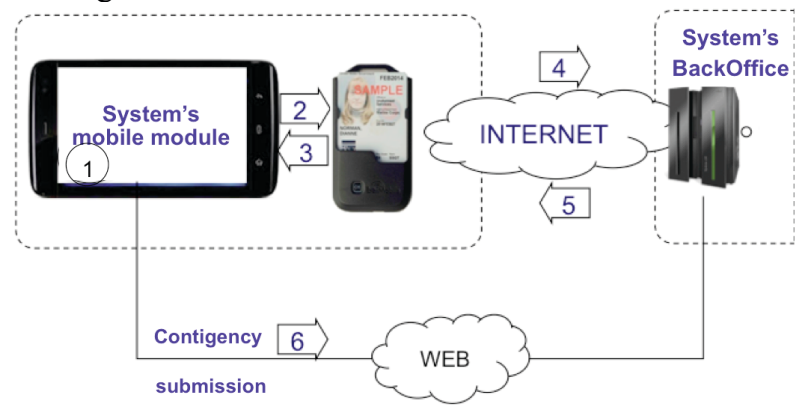

Figure 5. CA-e operational model: creation of a CA-e

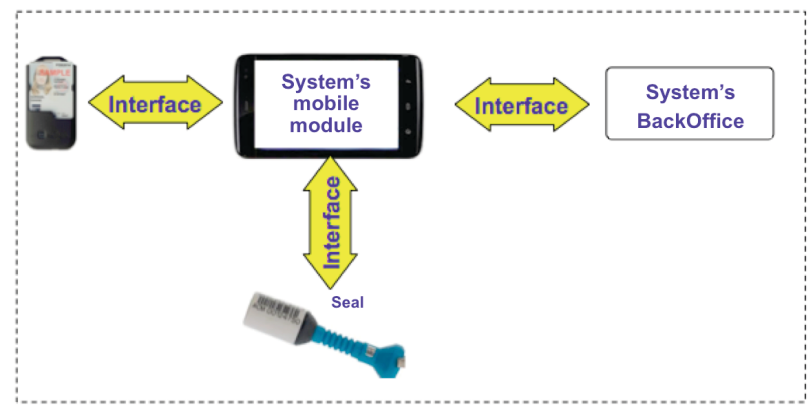

Figure 6. CA-e operational model: interfaces [3]

Note that the applied technologies are [2 and 3]:

1. RF-ID: Radio Frequency Identification

2. NFC: Near Field Identification
3. Cloud Computing

4. ICP-BRASIL: Public Keys Infrastructure

5. Mobility: mobile devices for field

6. Tamper proof: electronic detection of violations

7. XML: eXtensible Markup Language

After that, as shown in Fig. 7, the exporter (or his representative, usually a broker) will: 1 . electronically receive the information contained at the CA-e; 2. realize the traditional operational dispatch; and, 3. electronically receive a status return of the system.
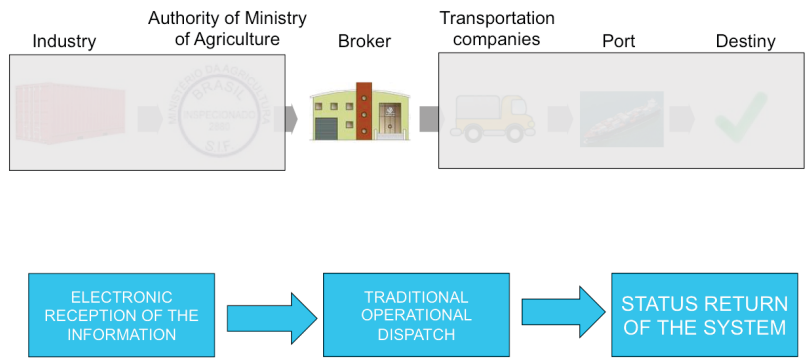

Figure 7. Brazilian animal protein exportation supply chain: processes realized by the broker

The transportation companies, as presented by Fig. 8, will take the cargo to the Port. During that way they can be subjected to non-intrusive inspection, by passing through a Radiofrequency Identification (RFID) portal.
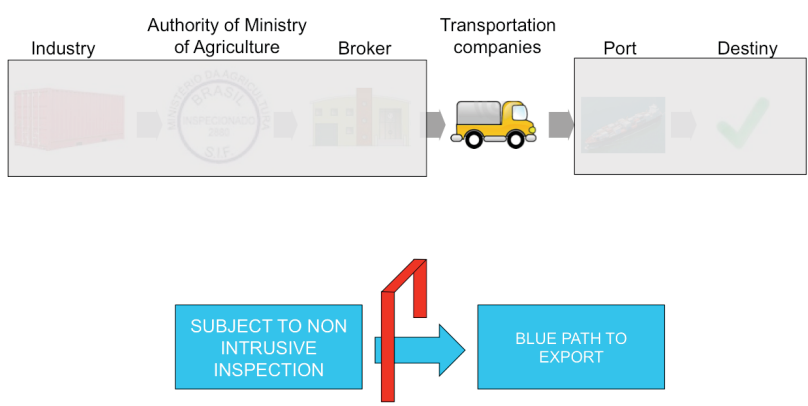

Figure 8. Brazilian animal protein exportation supply chain: processes realized by transportation companies

At last, as shown in Fig. 9, the sealed container arrives at the Port of Origen, where will be read the RFID on its seal. When the seal is read, the terminal operator can verify if the truck is clear to board or not, or if it has to be physically inspected by an agent of Vigiagro.

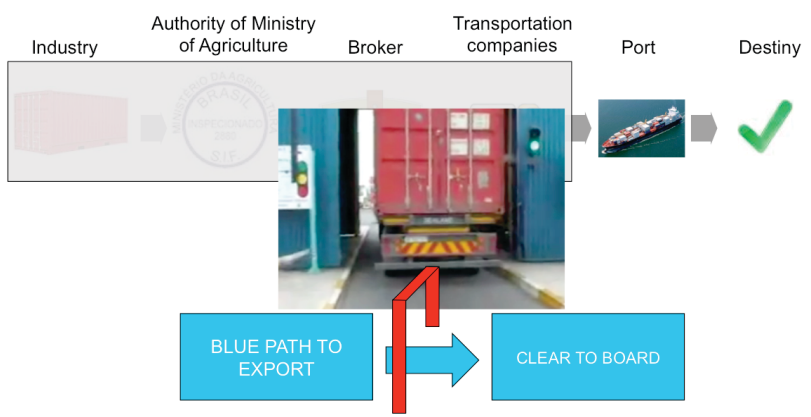

Figure 9. Brazilian animal protein exportation supply chain: processes realized at the Port 


\section{CA-e as an element of integration and traceability}

As said before, it is possible to diminish the amount of bureaucracy through Brazilian beef supply chain by adopting the CA-e on Brazilian territory. But, its adoption abroad can also diminish the bureaucracy of the process on the importer territory.

CA-e is a document "that exists exclusively in the digital format, is stored and delivered through electronically means, in order to document an operation of container sealing by SIF, with legal validity guaranteed by the digital signature based on digital certificates issued by ICP-BRAZIL.

ICP-BRAZIL is the official public key infrastructure in Brazil, since 2001, allowing electronic documents to be signed and recognized all over the national territory." [3] [5] [6]

It makes an interface between public and private systems, applying a communication machine-machine. Private systems are those of operational and supervision layers, such as SAP, Oracle, J. D. Edwards and others proprietary systems. Public systems are those of control layer, those that support compliance and procedures, such as governmental systems that users must input information to fulfill requirements. Brazilian examples are: Vigiagro's system (SIGVIG) and RFB's system (SISCOMEX). Fig. 10 presents reference architecture and technology: private and public layers. Fig. 11 presents CA-e function in those terms.

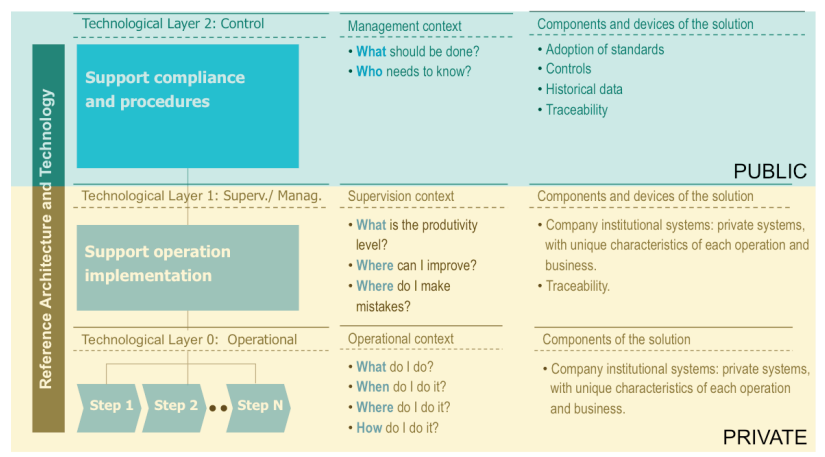

Figure 10. Reference architecture and technology: private and public layers

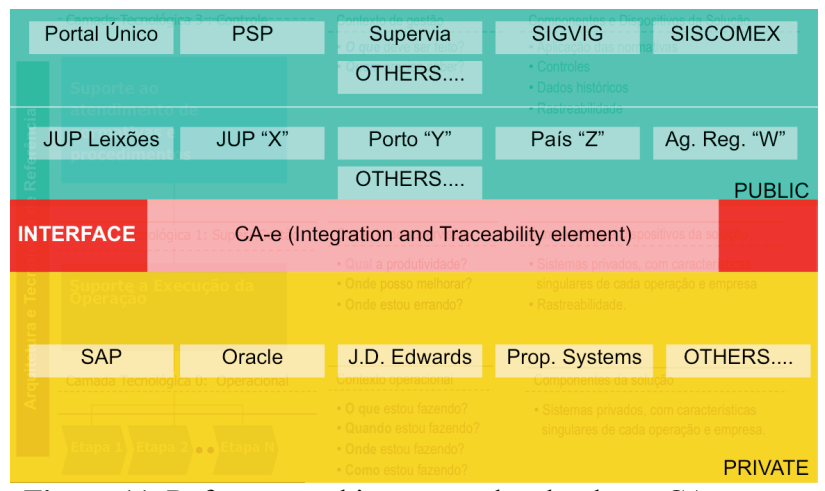

Figure 11. Reference architecture and technology: CA-e as an element of integration and traceability
In other words, it substitutes communications that nowadays still happens man-man or man-machine. Just by doing so, it avoids inefficiency, errors and rework.

\section{Proposed Solution}

Acting as an element of integration and traceability, the CA-e can optimize the supply chain. It can transfer all necessary information electronically, as presents Fig. 12.
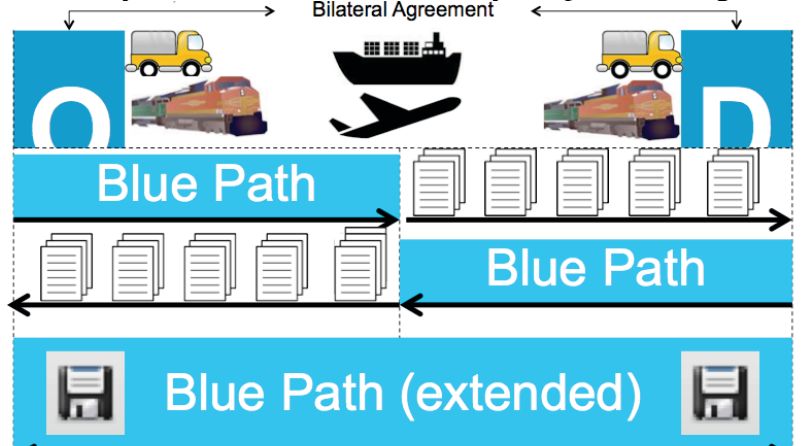

Figure 12. Extension of Blue Path (CA-e)

Presently the CA-e is in use in Brazil, so the information regarding the health supervision can be presented electronically as soon as an agent of SIF (an institution of MAPA) generates the CA-e. However, that e-Doc is not accepted at the destiny port, because of the absence of a bilateral agreement that allows so.

The extended CA-e would work on the following manner, as shown on Figs. :

1. The data present on a private system at the Origen is used to create the CA-e.

2. The data is automatically transferred to CA-e system.

3. The data is automatically transferred to the public system.

4. The public institution analyzes the data and, if everything is $\mathrm{OK}$, that cargo receives health clearance.

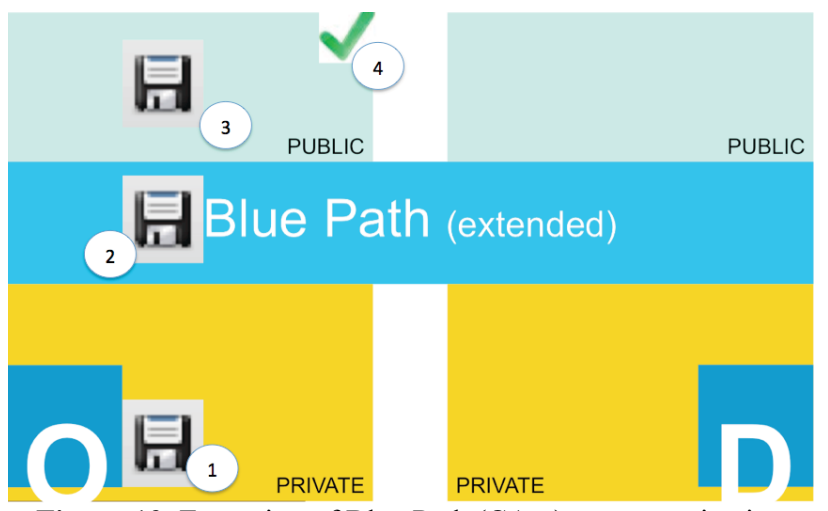

Figure 13. Extension of Blue Path (CA-e) - communication process at Origen

5. The data is automatically sent to the system at the destiny.

6. The data is automatically sent to the private system at the destiny. 
7. The private system recognizes the cargo as theirs and automatically informs the public system that he is going to receive such cargo.

8. Thus, the public system is ready to analyze and decide for the inspection, clearance or denial of the cargo.

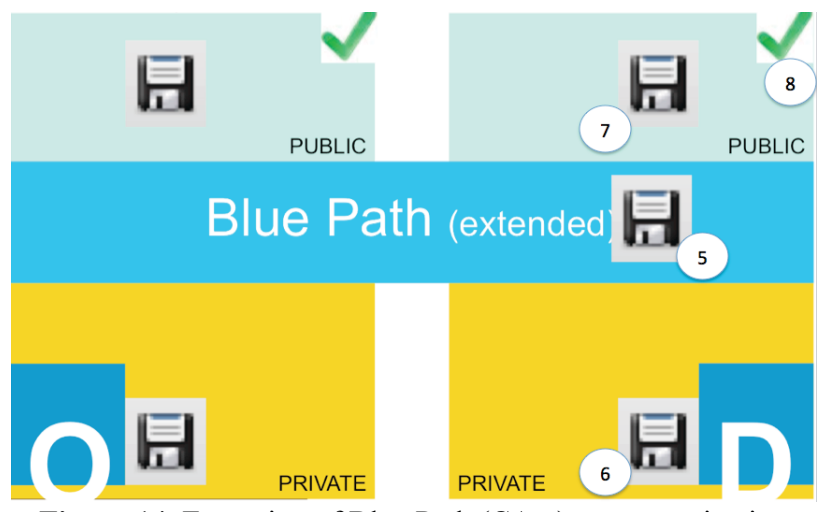

Figure 14. Extension of Blue Path (CA-e) - communication process at Destiny

9. Being cleared by the public authorities at the destiny, it will mean that the cargo was released prior to its arrival at the port of origin, because all the process will begin when the cargo leaves the industry. (Fig. 15)

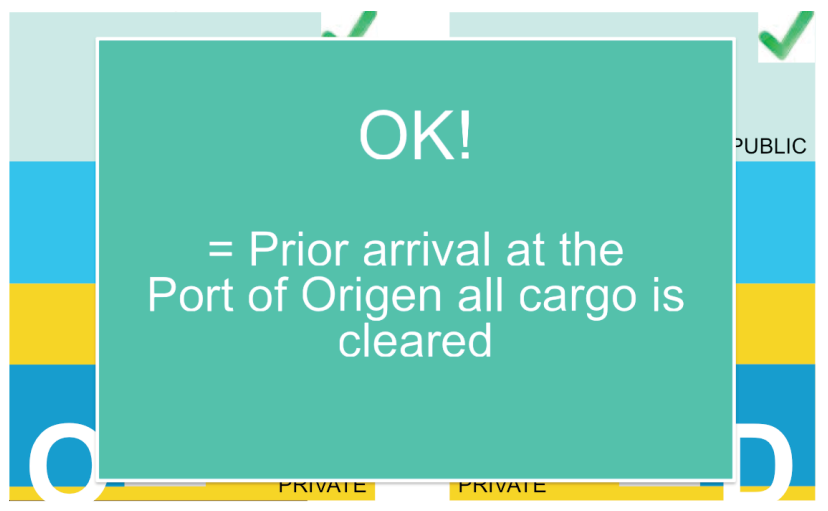

Figure 15. Extension of Blue Path (CA-e) - communication process, result expected

As previously said, the importer country can be impacted by the requirement of paper documents for the nationalization of the product, which would justify reviewing bilateral agreements to contemplate the acceptance by the authorities of an electronic document instead.

\section{Conclusions}

The CA-e is a tool that allows the automation of the communication between systems. It allows the communication machine/machine between systems. By substituting communications man/man and man/machine, it reduces errors, inefficiency and rework.

By extending the CA-e for the importer country all the exportation process will be followed, from beginning to end. In the case of the animal protein supply chain that means from the industry, passing through transportation companies, port of origin and destiny, until it gets to the importer.

That means that the CA-e guarantees traceability and visibility along the entire logistic chain, which makes powerful tool to improve its management efficiency, including the capacity to anticipate problems or errors and to reduce operational costs.

However, bilateral agreements must be changed in order to allow the adoption of e-Docs through the whole exportation and subsequently nationalization process.

\section{References}

1. A. Perego and A. Salgaro, Assessing the benefits of $B 2 B$ trade cycle integration: a model in the home appliances industry. Benchmarking: An International Journal, Vol. 17 Iss 4 pp. 616 - 631 (2010). Available at <http://dx.doi.org/10.1108/14635771011060611>. Accessed on 22/08/2014.

2. M. L. R. P. DIAS et al. Blue Path for exports of animal protein, Proceedings of the 12th WSEAS International Conference on Information Security and Privacy (ISP '13), Recent Advances in Computer Science (ISBN 978-960-474-354-4), pp. 134 - 140 (2013). Available at <http://www.wseas.us/elibrary/conferences/2013/Nanjing/ACCIS/ACCIS21.pdf $>$. Accessed on 30/04/2016.

3. M. L. R. P. DIAS et al. Customized e-Doc to expedite the Brazilian animal protein export process by sea, International Journal of Systems Applications, Engineering \& Development (ISSN: 2074-1308), v. 8, pp. 221 - 229 (2014). Available at $<$ http://www.naun.org/main/UPress/saed/2014/a0620 14-150.pdf $>$. Accessed on 30/04/2016.

4. The World Bank. "Trading Across Borders".

Available at

$<$ http://www.doingbusiness.org/data/exploretopics/tr ading-across-borders $>$. Accessed on 30/04/2016.

5. BRAZIL. Presidency of the Republic. Provisional Measure (MP) n. 2200-2 of 08/24/2001. Published on August, 24 of 2001. Available at $<$ http://www.planalto.gov.br/ccivil_03/mpv/An tigas_2001/2200-2.htm>. Accessed on 30/04/2016.

6. ITI (National Institute of Information Technology). Official public key infrastructure in Brazil (ICPBRASIL). Available at <http://www.iti.gov.br/icpbrasil/o-que-e>. Accessed on 30/04/2016. 